\title{
Rate and indications of cesarean section in the Maternity Teaching Hospital in Erbil City, Kurdistan region, Iraq
}

\begin{abstract}
Background and objective: Knowing the rate and indications of the cesarean section will help to have an overview of this common type of obstetrical procedure and to plan for the high level of care management. This study aimed to find out the rate of cesarean section and to identify its indications.

Methods: A cross-sectional study was conducted at the Maternity Teaching Hospital in Erbil city of Kurdistan Region, Iraq. Data were collected during the period of $20^{\text {th }}$ of March to $30^{\text {th }}$ of December 2015 by an interview with 722 women who were admitted to the hospital and underwent cesarean section out of 11881 cesarean section done during 2015. Results: Results showed the increasing rate of the cesarean section from $28.5 \%$ in 2010 to $35.77 \%$ in 2015 . The main overall indications for cesarean section were a previous cesarean section $(70.49 \%)$, cephalopelvic disproportion $(35.31 \%)$ and mother's request $(14.26 \%)$.

Conclusion: Rate of cesarean section is much higher than the optimal range recommended by the World Health Organization. Finding the appropriate strategies for decreasing the rate of primary and secondary indications is essential.
\end{abstract}

Keywords: Cesarean section; Indication; Rate; Kurdistan.

\section{Introduction}

Cesarean section (CS) is the delivery of an infant through an incision made in the woman's abdominal wall and uterus. This type of delivery occurs in cases where vaginal delivery is questionable or a condition warrants immediate delivery for the well-being of the infant and mother. ${ }^{1}$ CS significantly reduce maternal and perinatal mortality.$^{2}$ The WHO considers CS rates of $5-15 \%$ to be the optimal range for the targeted provision of this life saving intervention for mother and infant; ${ }^{3}$ lower rates suggest the unmet need, while higher rates suggest an improper selection. However, access to safe CS in resourcelimited settings is much lower, estimated at $1-2 \%$ reported in sub-Saharan Africa. ${ }^{4}$ The indications for cesarean sections are usually maternal, fetal, physician related factors or a mixture of the three. The overall CS rates have increased progressively over many parts of the world. ${ }^{5} \mathrm{CS}$ is a major surgical procedure with possibly serious consequences and should be performed in the presence of specific and clearly defined indications. Infection, thromboembolic disorders are the most common causes of morbidity and mortality among women who undergo CS. Approximately, $10 \%$ of deliveries are considered as high risk, some of which may require $\mathrm{CS}$. Its prevalence ranges from $4 \%$ in Africa to $29 \%$ in Latin America and the Caribbean. In recent years the rate has risen to a record level of $46 \%$ in China and $25 \%$ or above in many Asian and European countries, Latin America and USA. ${ }^{5-7}$ Definite indications of CS are cephalopelvic disproportion, a major degree of placenta previa and higher order multiple pregnancy. The possible indications are a breech presentation, moderate to severe pre-eclampsia,

* Department of Midwifery, College of Nursing, Hawler Medical University, Erbil, Iraq.

** Department of Community Medicine, College of Medicine, Hawler Medical University, Erbil, Iraq. 
a maternal condition that warrants the exclusion of maternal effort, diabetes mellitus, intrauterine growth restriction, antepartum hemorrhage and certain fetal abnormalities. $^{8}$ Knowing the rate and indication of CS in Kurdistan will help to have an overview of this type of obstetrical procedure and to plan for the high level of care management. So the researchers were interested in studying this subject, aiming to find out the rate of cesarean section and to identify its indications in the Maternity Teaching Hospital in Erbil city.

\section{Methods}

A cross-sectional study was conducted at the Maternity Teaching Hospital in Erbil city of Kurdistan Region/Iraq. A convenience sample of 722 women (who were present in the hospital during the availability of the researcher in the mentioned hospital) were included in the study; knowing that the researcher was available in the hospital for two days per week (12 hours/day). None of the women refused to participate in the study. Data were collected during the period of $1^{\text {st }}$ of April to $30^{\text {th }}$ of December 2015 by an interview with the above mentioned women. The researcher developed a questionnaire for data collection, which included demographic and obstetrical data, together with primary and secondary indications of CS. Data related to the rate of CS of the years 2010 to 2015 were taken from the hospital registers. The study protocol was approved by scientific and ethics committees of the College of Nursing/Hawler Medical University. Before data collection, formal permission was taken from Erbil General Directorate of Health and the Maternity Teaching Hospital. The purpose of the study was explained to the women, and verbal consent was taken from them for participation in the study. Data were analyzed using the statistical package for social sciences (SPSS, version 19). The Chi-square test was used to compare the CS rate of each year with that of the year 2015. A $P$ value of $\leq 0.05$ was considered as statistically significant.

\section{Results}

The results of the present study indicated an increase in the rate of CS from $28.5 \%$ in 2010 to $35.77 \%$ in 2015 (Table 1).

Table 1: Rate of CS of the Maternity Teaching Hospital from 2010 - 2015.

\begin{tabular}{lcccc}
\hline Year & Total births & Cesarean section & Rate of cesarean section \% & $P$ value* \\
\hline 2010 & 23956 & 6829 & 28.5 & $<0.001$ \\
$\mathbf{2 0 1 1}$ & 25055 & 7072 & 28.2 & $<0.001$ \\
$\mathbf{2 0 1 2}$ & 26600 & 8715 & 32.7 & $<0.001$ \\
$\mathbf{2 0 1 3}$ & 28903 & 10569 & 36.5 & 0.04 \\
$\mathbf{2 0 1 4}$ & 32907 & 12621 & 38.3 & $<0.001$ \\
$\mathbf{2 0 1 5}$ & 33209 & 11881 & 35.77 & Reference \\
\hline
\end{tabular}

*The rate of CS of each year was compared with the rate of the year 2015. 
More than half $(55.5 \%)$ of the study sample living in the city of Erbil constituted $61.7 \%$ were in the age group 20-29 years, and $51 \%$ had been graduated from basic schools. The mean \pm SD of age was $28.1 \pm 5.4$ years, and that of the years of education was $6.4 \pm 5.2$ years. Those of the sample. The majority $(83.5 \%)$ of the mothers were multiparous, and $72 \%$ of them had the previous history of CS. The highest percentage $(86.6 \%)$ of the sample had elective CS (Table 2).

Table 2: Demographic and obstetric characteristics of the study sample.

\begin{tabular}{|c|c|c|c|}
\hline Variables & No. & $\%$ & Mean \pm SD \\
\hline Age (year) & & & $28.1 \pm 5.48$ years \\
\hline$\leq 19$ & 29 & 4.1 & \\
\hline $20-29$ & 401 & 55.5 & \\
\hline $30-39$ & 271 & 37.5 & \\
\hline$\geq 40$ & 21 & 2.9 & \\
\hline Level of education & & & $6.4 \pm 5.25$ years \\
\hline Illiterate & 166 & 23 & \\
\hline Basic school & 368 & 51 & \\
\hline Secondary school & 88 & 12.2 & \\
\hline Institute and above & 100 & 13.8 & \\
\hline \multicolumn{4}{|l|}{ Residency } \\
\hline Inside city & 446 & 61.7 & \\
\hline Outside city & 276 & 38.3 & \\
\hline \multicolumn{4}{|l|}{ Parity } \\
\hline Primipara & 119 & 16.5 & \\
\hline Multipara & 603 & 83.5 & \\
\hline \multicolumn{4}{|c|}{ Previous history of CS } \\
\hline Yes & 520 & 72 & \\
\hline No & 202 & 28 & \\
\hline \multicolumn{4}{|l|}{ Type of CS } \\
\hline Elective & 625 & 86.6 & \\
\hline Emergency & 97 & 13.4 & \\
\hline Total & 722 & 100 & \\
\hline
\end{tabular}


The main overall indications for CS were previous CS $(70.49 \%)$, cephalopelvic disproportion (35.31\%) and mother's request $(14.26 \%) \quad$ (Table 3$)$. Mother's request $(36.63 \%)$, cephalopelvic disproportion (17.32\%), abnormal lie and presentation $(16.83 \%)$, failure of labor progress/indication (10.89\%) and bad obstetrical history/infertility (10.39\%) were as highest percentage primary indications of CS (Table 4).

Table 3: Overall indication for cesarean section.

\begin{tabular}{lcc}
\hline Indications & No. & \% (n = 722) \\
\hline Previous CS & 509 & 70.49 \\
Cephalopelvic disproportion & 255 & 35.31 \\
Mother request & 103 & 14.26 \\
Abnormal lie and presentation & 79 & 10.94 \\
Fresh scar & 78 & 10.80 \\
Bad obstetrical history/Infertility & 77 & 10.66 \\
Failure of labor progress/induction & 37 & 5.12 \\
Preeclampsia/eclampsia & 30 & 4.12 \\
Fetal distress & 18 & 2.49 \\
Multiple pregnancy & 16 & 2.21 \\
Oligohydramnious & 15 & 2.07 \\
Previous AP repair & 12 & 1.66 \\
Antepartum hemorrhage & 11 & 1.52 \\
Post-term & 9 & 1.24 \\
Tubal ligation & 7 & 0.96 \\
Placenta previa & 7 & 0.96 \\
Diabetes mellitus/gestational diabetes & 6 & 0.83 \\
Hydrocephalous & 4 & 0.55 \\
IVF & 3 & 0.41 \\
Cord prolapse & 2 & 0.27 \\
Wart & 1 & 0.13 \\
Big Bartholin cyst & 1 & 0.13 \\
Congenital anomaly & 1 & 0.13 \\
Rupture of uterus & 1 & 0.13 \\
\hline
\end{tabular}

Table 4: Indications of primary CSs

\begin{tabular}{lcc}
\hline Indications & No & \% (n = 202) \\
\hline Mother request & 74 & 36.63 \\
Cephalopelvic disproportion & 35 & 17.32 \\
Abnormal lie and presentation & 34 & 16.83 \\
Failure of labor progress/induction & 22 & 10.89 \\
Bad obstetrical history/Infertility & 21 & 10.39 \\
Fetal distress & 15 & 7.42 \\
Multiple pregnancy & 10 & 4.95 \\
Previous AP repair & 9 & 4.45 \\
Preeclampsia/eclampsia & 8 & 3.96 \\
Placenta previa & 5 & 2.47 \\
Antepartum hemorrhage & 2 & 0.99 \\
Cord prolapse & 1 & 0.49 \\
\hline \hline
\end{tabular}


Table 5 shows that $97.11 \%$ of and bad obstetrical history $(10.76 \%)$ indications for repeated CS were previous CS. The other indications with the highest percentage were cephalopelvic disproportion (42.3\%), fresh scar (14.23\%) (Table 5). There was a statistically significant association between type of CS with parity and previous CS (Table 6).

Table 5: Indications of repeated CS.

\begin{tabular}{lcc}
\hline Indications & No & \% ( $\mathbf{n}=\mathbf{5 2 0})$ \\
\hline Previous CS & 505 & 97.11 \\
Cephalopelvic disproportion & 220 & 42.3 \\
Fresh scar & 74 & 14.23 \\
Bad obstetrical history/Infertility & 56 & 10.76 \\
Abnormal lie and presentation & 45 & 8.62 \\
Mother request & 29 & 5.57 \\
Preeclampsia/eclampsia & 22 & 4.23 \\
Failure of labor progress/induction & 15 & 2.88 \\
Multiple pregnancy & 6 & 1.15 \\
Antepartum hemorrhage & 5 & 0.96 \\
Fetal distress & 3 & 0.57 \\
Previous AP repair & 3 & 0.57 \\
Placenta previa & 2 & 0.38 \\
Cord prolapse & 1 & 0.19 \\
\hline
\end{tabular}

Table 6: Association of type of cesarean section with age, parity and previous CS.

\begin{tabular}{lccc}
\hline Variables & \multicolumn{2}{c}{ Type of CS } & Planned \\
N0.(\%) & $\begin{array}{c}\text { Emergency } \\
\text { N0.(\%) }\end{array}$ & \\
\hline Age & $26(89.7)$ & $3(10.3)$ & \\
$\leq 19$ & $337(84)$ & $64(16)$ & $0.193^{*}$ \\
$20-29$ & $243(89.7)$ & $28(10.3)$ & \\
$30-39$ & $19(90.5)$ & $2(9.5)$ & \\
$\geq 40$ & & & $<0.001$ \\
Parity & $89(74.8)$ & $30(25.2)$ & \\
Primi & $536(88.6)$ & $67(11.1)$ & \\
Multi & & & $<0.001$ \\
Previous CS & $474(91.2)$ & $46(8.8)$ & \\
Yes & $151(74.8)$ & $51(25.2)$ & \\
No & & & \\
\hline
\end{tabular}




\section{Discussion}

The rate of CS in the present study was $35.77 \%$ in 2015 which is $7 \%$ more than the rate of 2010. The rate of CS at Al-Batool Maternity Teaching hospital in Mosul / Iraq was $17.94 \%$ in $2003 .{ }^{9}$ The rate of CS in the Maternity Teaching Hospital in another city of Kurdistan (Duhok) was $32.2 \%$, in 2014 . $^{10}$ The prevalence of CS in a Teaching Hospital in Pakistan was $21.40 \% .^{11}$ In Tanzania, at St. Joseph Medical Hospital, the rate of $\mathrm{CS}$ was $18 \% .^{12}$ In a tertiary referral center in Eastern Nepal, the rate of cesarean section was $33.7 \%$ (in 2007) which is almost similar to results of the present study. ${ }^{13}$ According to a report by the WHO in 2010, the rate of CS in neighboring countries of Iraq was as follows: Iran $41.9 \%$, Turkey $21.2 \%$, Jordan $18.2 \% .{ }^{14}$ The results of a study done by Abu Omer and Abu Anza in Jordan, the CS rate was $18.75 \%$ in $2010 .{ }^{15}$ In three sub-Saharan African countries the rate was $6.2 \%$ during $2010-2011 . .^{16}$ In low income countries, there is an additional need for 0.8 - 3.2 million CS, every year, where $60 \%$ of the world's births occur. Simultaneously, 4.0-6.2 million CS in excess are performed in middle and high income countries where $37.5 \%$ of the births occur. Those CS in excess are likely to be medically unjustified and should be then considered unnecessary $\mathrm{CS} .{ }^{14}$ It is worth to mention that the hospital rate of CS is an inflated rate (as many NVDs are attended by midwives), however, the Maternity Teaching Hospital is the main maternity hospital in Erbil and most of the deliveries (NVD and CS) are referred to that hospital; moreover, many CS deliveries are referred to the private hospitals which will decrease the rate of $\mathrm{CS}$ in the maternity teaching hospital. The highest overall indication of cesarean section in the present study was previous CS $(70.49 \%)$. In the repeated CSs, previous CS constituted $97.11 \%$ of the indications. Cephalopevic disproportion, mother request, abnormal lie and presentation, fresh scar, bad obstetrical history and infertility, failure of labor progress/induction, preeclampsia/ eclampsia, fetal distress had more frequency than other indications. In a study done in Duhok city of Kurdistan region / Iraq, the rate of 'repeated CS' was $50.7 \%$, although it was less than the results of the present study it was the first indication of CS. Emergency-risk to baby (20.28\%), breech presentation (17.95\%), unknown $(17.27 \%)$, emergency-risk to mother $(13.12 \%)$ and exhaustion after long labor $(10.22 \%)$ were the main reasons of first CS, almost similar to results of the present study. ${ }^{10}$ Hafeez et al. reported the previous CS, failure progress of labour, fetal distress and breech presentation as main indications of CS. ${ }^{11}$ In a Jordanian study, failure of progress and fetal distress were the main indications of CS in the overall and primary indication of CS. Previous CS was the main indication in repeated CSs. ${ }^{15}$ The results of the present study is similar to results of a study done in Ghana in which previous CS, fetal distress, malpresentation, failure in progress, cephalopelvic disproportion, preeclampsia/ eclampsia and antepartum hemorrhage were the main indications of $\mathrm{CS}^{16}$ In a study in Tanzania, prolonged/obstructed, abnormal presentation, previous CS and fetal distress were the most common indications of CS. ${ }^{17}$ Gulati and Hjelde found a statistically significant association between type of CS with age, parity and previous CS, which agreed with results of the present study regarding parity and previous CS. ${ }^{17}$ Findings of the present study show that mother request for performing CS is the first primary indication and the majority of mothers underwent CS because of having previous CS. Further researches are essential to findings effective strategies for decreasing the rate of the repeated CS as well as evaluation of obstetrician clinical decision making and quality of care in the 1st stage of labor by midwives. Analysis of the attitude of health care providers and women may be helpful in decreasing the rate of CS. A limitation of the study is the convenience method of 
sampling used rather than a random sampling which will affect the generalizability of the study. The authors believe that CS cases included during the availability of the researcher (two days/ week) do not differ from those available in the other days of the week, hence no great effect on the generalizability. A ' $0 \%$ ' non-response rate is considered a strength of the study. None of the women refused to participate which could be attributed to the fact that they are in-patients and hence they have time and willingness to do the interview, in addition to that women in Kurdish community usually respect the medical staff and it is expected that they cooperate with them.

\section{Conclusion}

The rate of hospital-based CS is much higher than optimal range recommended by $\mathrm{WHO}$. Finding the appropriate strategies for decreasing the rate of primary and secondary indications is essential.

\section{Competing interests}

The authors declare that they have no competing interests.

\section{References}

1. Matteson P. Women's health during the childbearing years. St. Louis: Mosby; 2001. P. 569.

2. Weil $\mathrm{O}$, Fernandez $\mathrm{H}$. Is safe motherhood an orphan initiative? Lancet 1999; 354:940-3.

3. World Health Organization. Appropriate technology for birth. Lancet 1985; 2(8452):436-7.

4. Betran AP, Merialdi M, Lauer JA, Bing-Shun W, Thomas J, look PV, et al. Rates of caesarean section: analysis of global, regional and national estimates. Paediatr Perinat Epidemiol 2007; 21:98-113.

5. Zhang J, Troendle J, Reddy UM, Luoghon SK, Branch DW, Burkman R. Contemporary cesarean delivery in the United States. Am J Obstet Gynecol 2010; 203(4):326.e1-10.

6. Stavrou EP, Ford JB, Shand AW, Morris MJ, Robert CL. Epidemiology and trends for Cesarean section births in New South Wales, Australia: a population-based study. BMC Pregnancy Childbirth 2011; 11:8.

7. MBC NEWS. Caesarean section rate around globe at epidemic level. 2011. (Accessed Oct 10, 2015, at http://www.nbcnews.com/id/34826186/ \#.Vyzec1KDS10).
8. Fraser DM, Cooper MA. Myels textbook for midwives. China: Elsevir limited China; 2009.

9. Jarjees YT. Cesarean section rates at Al-Batool Maternity Teaching Hospital. Al-Kindy Col Med J 2011; 7(1):1-3.

10. Shahab FI. Pattern of cesarean section at Maternity Hospital in Duhok City/ Iraq-Kurdistan Region. Ph.D. Thesis in Community Medicine. Kurdistan Board for Medical Specialties, Dohuk, Iraq; 2015.

11. Hafeez M, Yasin A, Badar N, Pasha MI, Akram N, Gulzar B. Prevalence and indications of cesarean section in a teaching hospital. JIMSA 2014; 27(1):15-6.

12. Becher L, Stokke S. Indications for cesarean section in ST. Joseph Medical Hospital Moshi, Tanzania. Ph.D. Thesis in OB-GYN. University of Oslo, Norway; 2013.

13. Shhetri S, Singh U. Cesarean section: its rates and indications at a tertiary referral center in Eastern Nepal. Health Renaissance 2011; 9(3): 179-83.

14. Gibbons L, Belizán JM, Lauer JA, Betrán AP, Merialdi M, Althabe F. The Global Numbers and Costs of Additionally Needed and Unnecessary Caesarean Sections Performed per Year: Overuse as a Barrier to Universal Coverage. World Health Report; 2010. (Accessed 10, 2016, at http://www.who.int/healthsystems/topics/ financing/healthreport/30C-sectioncosts.pdf).

15. Abu-Omar A, Abu-Anza SH. Frequency rate and indications of cesarean sections at Prince Zaid Bin Al Hussein Hospital-Jordan. JRMS 2012; 19(1):82-6.

16. Chu K, Cortier H, Maldonda F, Mashant $T$, Ford N, Trelles $M$. Cesarean section rates and indications in Sub-Saharan Africa: A multi-Country study from Medecins sans Frontieres. PLoS ONE 2012; 7(9):e44484.

17. Gulati D, Hjelde Gl. Indications for cesarean section at Korle Bu Teaching Hospital Ghana. PhD Thesis. University of Oslo, Norway; 2012. 